\title{
Profiting from Mean-Reverting Yield Curve Trading Strategies*
}

\author{
Choong Tze Chua ${ }^{a}$, Winston T.H. Koh, ${ }^{b}$ Krishna Ramaswamy ${ }^{c}$
}

February 2004

\begin{abstract}
A large class of fixed income trading strategies focuses on opportunities offered by the interest rate term structure. This paper studies a set of yield curve trading strategies that are based on the view that the yield curve mean-reverts to an unconditional curve. These mean-reverting trading strategies exploit deviations in the level, slope and curvature of the yield curve from historical norms. We consider cash-neutral trades with one-month holding periods. Some mean-reverting strategies were found to be highly profitable, and outperform, on a risk-adjusted basis before transaction costs, alternative strategies of an investment in the Lehman Brothers Bond index (by up to 5.9 times) and an investment in the S\&P index (by up to 5.1 times). Even after accounting for transaction costs, some of these strategies are still significantly more profitable than the benchmarks. Furthermore, transaction costs can be reduced substantially by changing the trading frequency or through structured derivative trades. We found evidence that market efficiency has improved, and the scope for excess returns has diminished since the late 1980s.
\end{abstract}

Keywords: yield curve, fixed income trading, market efficiency, Treasury bonds

Research support from the Wharton-SMU Research Centre, Singapore Management University is gratefully acknowledged.

a School of Business, Singapore Management University, 469 Bukit Timah Road, Singapore 259756. Tel: +65-68220745; Email: ctchua@smu.edu.sg

$b \quad$ School of Economics and Social Sciences, Singapore Management University, 469 Bukit Timah Road, Singapore 259756. Tel: +65-68220853; Email: winstonkoh@smu.edu.sg

c The Wharton School, University of Pennsylvania, 3259 Steinberg-Dietrich Hall, Philadelphia, PA 19104, USA. Tel: +215 8986206; Email: krishna@wharton.upenn.edu. 


\section{Introduction}

Trading in fixed income assets is a profitable business in global investment banks. Besides providing market liquidity through market-making activities, investment banks also devote significant amounts of proprietary capital to trade a wide variety of fixed income instruments, such as Treasury bills to 30 -year government bonds, corporate bonds and mortgage-backed securities, etc. Besides investment banks, hedge funds and dedicated bond funds also actively pursue trading opportunities in fixed income assets.

The strategies deployed range from simple arbitrage-trading, to complex trades based on technical or market views on the term structures of interest rates and credit risks. These yield curve trading strategies are essentially bets on changes in the term structure. These trading strategies can be broadly classified as directional and relative-value plays. Directional trading, as the name implies, are bets on changes in the interest rates in specific directions. Relative-value trading, by contrast, focuses on the market view that the unconditional yield curve is upward sloping, and that the current yield curve would mean-revert to an unconditional yield curve. A wide variety of trading techniques are used to construct relative-value trades based on this market view. However, there have been few efforts to examine the performance of these trading strategies or to compare them with equity investment strategies. Litterman and Scheinkman (1991), Mann and Ramanlal (1997) and Drakos (2001) are recent studies on the subject.

In this paper, we analyze the performance a specific class of such relative-value trading techniques that are directly implied by the notion that mean-reversion of the yield curve occurs. We consciously avoid "data-snooping" by not searching through a large number of possible strategies to find a few that are profitable. Instead, we start from the market view that the yield curve mean-reverts and derive trading strategies that follows most naturally from such a view - if the level, spread or curvature is higher (lower) than the historical average, bet that the level, spread or curvature, respectively, will decrease 
(increase) towards the historical average. We shall refer to this class of technical trading strategies as "mean-reverting" trading strategies. Following Litterman and Scheinkman (1991), we consider the three aspects of the yield curve - namely, the interest rate level, the slope (i.e. yield spread) and the curvature - and construct a portfolio of yield-curve trading strategies centering on each aspect. To facilitate a consistent comparison of their performance, we impose cash neutrality and consider one-month holding period for each category of strategies, and adjust the payoff for risk, as measured by the standard deviation of the payoffs. Our study abstract from credit risk --in particular, default risk and chose as our dataset the U.S. Treasury interest rates, from the period 1964 to 2000 for our study. For each aspect of the yield curve, we consider strategies that trade on the whole yield curve, as well as strategies that trade on individual portions of the yield curve.

Our analysis shows that there exists a set of mean-reverting trades that appear to offer, on average, superior payoffs, even after accounting for transaction costs, over the period considered in our study. We compare these payoffs to two benchmarks. The first benchmark is a commonly deployed fixed income strategy referred to as riding the yield curve. This involves essentially buying fixed income assets and selling them before maturity to earn the term risk premium. (see Stigum and Fabozzi (1987), pp 271). The second benchmark involves a risk-adjusted strategy of investing in the S\&P index, and funding the trade by shorting one-month U.S Treasury bills.

In this comparison, we found that some yield curve strategies outperform the S\&P strategy by about 5.1 times, and the Lehman Brothers Bond index strategy about 5.9 times, based on a comparison of the risk-adjusted average gross payoffs. There is evidence that market efficiency appeared to have improved over time, and the scope for excess returns has diminished. We also found that the implied transaction costs that would have eliminated the excess returns from the set profitable mean-reverting yield curve trades is of the order of about $0.01 \%$ of the value of bonds traded - which is less 
than the current transaction cost in the market for U.S. Treasury bills (but not Treasury bonds).

While factoring in trading costs may appear to diminish the profits from some of the mean-reverting yield curve trades (although one of the strategies still return profits that were significantly higher than the benchmarks, even after accounting for transaction costs), we must add that the implied transaction cost we calculated is based on the assumption of entering and exiting each yield curve trading strategy on a monthly basis. The transaction costs can be significantly reduced by structuring derivative trades on a notional basis, mirroring the economic cashflows of the underlying yield curve trades but without actually funding and holding the bonds. These derivative trades are commonly carried out in the fixed income market. Hence, the potential remains for more meanreverting yield curve strategies to yield significant positive returns.

The rest of the paper is structured as follows. In Section 2, we briefly discuss the theory of the interest rate term structure, and describe the construction of the dataset, the various classes of mean-reverting yield curve trading strategies that we examine, as well as the two benchmarks used for comparison. Section 3 presents the results, and discusses their relative performance of the different yield curve strategies against each other. We further compare the performance of a set of profitable yield curve strategies against the two benchmarks. Section 4 concludes the paper with suggestions for further research.

\section{Mean-Reverting Yield Curve Strategies}

There is a wide variety of yield curve trading strategies. The literature on yield curve trading dates back to the late 1960s; a sample of the earlier literature includes De Leonardis (1966), Freund (1970), Darst (1975), Weberman (1976), Dyl and Joehnk (1981) and Stigum and Fabozzi (1987). More recent analysis of the subject are found in 
Jones (1991), Mann and Ramanlal (1997), Grieves and Marchus (1992), Willner (1996) and Palaez (1997).

Our focus in this paper is on yield curve trading strategies that are based on the conventional fixed income view that the yield curve mean-reverts to some historical norm. This market view is consistent with historical experience. For instance, U.S. Treasury bill rates, spreads and curvature all trade within tight, finite bounds. The interest rate term structures in other countries also exhibit similar patterns. This suggests that some form of mean-reversion mechanism is at work that prevents the yield curve from drifting to extreme levels or shapes over time.

The market view of yield curve mean-reversion is also represented in theoretical models of the interest rate term structure - as discussed in Vasicek (1977), Cox, Ingersoll and Ross (1981, 1985), and Campbell and Shiller (1991), for example - which incorporate some form of mean-reversion mechanisms and are based on some form of the expectations hypothesis. ${ }^{1}$ In essence, the pure expectations hypothesis of the term structure is the theory that the long-term interest rate is the average of the current and expected short-term rates, so that the yield spread is mean-reverting. ${ }^{2}$ Interest rates along the yield curve adjust to equalize the expected returns on short- and long-term investment strategies. $^{3}$ Furthermore, by incorporating rational expectations, the pure expectations hypothesis implies that excess returns on long bonds over short bonds are unforecastable, with a zero mean in the case of the pure expectations hypothesis. Any arbitrage opportunity should be captured and realized by investors immediately. Therefore, by the

\footnotetext{
${ }^{1}$ Shiller (1990), Campbell (1995) and Fisher (2001) provide surveys of the literature on interest rate term structure.

2 This was first propounded by Fisher (1986) and refined by Lutz (1940) and Meiselman (1962).

3 A weaker version, referred to as the expectations hypothesis, states that the difference between the expected returns on short- and long-term fixed income investment strategies is constant, although it need not be zero as required under the pure expectations hypothesis.
} 
pure expectations hypothesis, yield curve trading strategies attempting to exploit anomalies or mis-pricings in the term structure would not yield consistently positive payoffs.

The expectations hypothesis of the term structure, therefore, stands in contrast to the practitioner's view that it is possible to construct mean-reverting yield curve trading strategies to generate consistent positive payoffs. Broadly speaking, mean-reverting yield curve strategies attempt to take advantage of deviations in the current yield curve relative to an unconditional yield curve. Three commonly-used trades are: (a) bullet strategy, which is constructed so that maturities of bonds are concentrated at a particular part of the yield; (b) ladder strategy, which involve investments across a range of maturities; and (c) barbell strategy, which are constructed, for example, by investing in two ends of the yield curve, and shorting the middle portion, or vice versa (see Fabozzi, 1996). It is easy to see that bullet strategies are essentially bets on the level of the interest rates, while ladder strategies and barbell strategies are bets on the yield spreads and curvatures, respectively.

There have not been systematic efforts to examine the performance of these trading strategies, and relate them to the predictions of the expectations hypothesis. An exception is Culbertson (1957) who computed and graphed holding period returns, between one week and three weeks, for short and various long term Treasury securities. He found that the holding period returns were very different from observed spot interest rates, and concluded that the pure expectations hypothesis, as propounded by Lutz (1940) did not hold.

The predictability of the spot yield curve and the forward interest rates, as implied by the expectations hypothesis, has also not found unambiguous empirical support (see Hamburger and Platt, 1975). Shiller, Campbell and Schoenholtz (1983) showed that the term structure does not provide information on the future change in the 
short-term rates. Moreover, as Cox, Ingersoll and Ross (1985) first showed, the different versions of the expectations hypothesis are not theoretically consistent. Mankiw and Miron (1986) also found that the predictability of the term structure disappears after the founding of the Federal Reserve. Subsequent work by Rudebusch (1995) and Balduzzi, Bertola and Foresi (1997) also found that changes in the interest rate were due to unexpected changes in the Fed targeting.

\subsection{Data}

The dataset we use for our study is the Fama-Bliss dataset obtained from CRSP (Centre for Research in Securities Prices, 2000). The data set contains monthly data on zero coupon yields derived from a yield curve of U.S. government Treasury bills and bonds from 30 June 1964 to 29 December 2000. For the purpose of this study, we express all zero coupon yields in the form of continuously compounded yields. These zero-coupon yields are of maturities that are approximately 1-month, 2-month,..., 12month, 24-month, 36-month, 48-month and 60-month. The observed maturities are approximate in the sense that some bonds may be of 0.9 month, 3.3 month or 11.8 month in maturities. Moreover, the observation interval for each yield curve is only approximately one-month apart (e.g. 28 days or 33 days). The total number of yield curve observations in our dataset is 439 .

For the purpose of our study, we regularize the dataset. This is carried out in two steps. First, we perform a cross-sectional linear interpolation to each zero yield curve in order to obtain the yields at monthly tenors from 1-month to 60-month. For instance, if the observed yields are 9.8 months, 11.3 months and 12.3 months, we interpolate linearly to obtain the yields for the 10-month, 11 month and 12-month tenors. Similarly, for yields of 12.3 month and 24.5 months, for example, we linearly interpolate to obtain yields for maturities of 13 -month, 14 month,..., 24 months, etc. The process is repeated 
for the rest of the yield curve. For our analysis, we shall refer to bonds with yields that are observed in the market as 'primary' bonds, and bonds with maturities that are not observed in the market as 'hypothetical' bonds. Hypothetical bonds therefore have maturities greater than 12 months, but are not divisible by 12 . The distinction is made to facilitate a comparison of alternative yield curve strategies in our analysis.

The second step that we took to regularize the dataset is a temporal linear interpolation procedure. The following example explains the procedure. Suppose the interpolated 13-month yield are observed at three dates, 7\% (date 0), 7.5\% (28 days later) and $6 \%$ (another 33 days later). Since we focus on a holding period of one month, we require the yield curves to be at exactly one-month intervals, in order to calculate the payoff at the end of each holding period. For our purpose, we define this to be 365.25 days divided by 12 , i.e. 30.4375 days. Hence, the temporally interpolated 13 -month yield in this example are 7\% (date 0), 7.3892\% (30.4375 days) and 6.0057\% (another 30.4375 days later).

Since the holding period of each trade is one-month, the relevant forward yield curve with which to compare against the unconditional yield curve is the one-month forward yield curve. The one-month forward interest rate at a maturity of $X$ months is calculated as follows. Let $r_{X, 0}$ denote the current interest rate while $r_{X, 1}$ denote the onemonth forward interest rate. We have

$$
e^{r_{x, 1} \frac{x}{12}} \cdot e^{r_{1,0} \frac{1}{12}}=e^{r_{x+1,0} \frac{x+1}{12}}
$$

Finally, the unconditional yield at each maturity (for primary and hypothetical bonds) at any date is calculated as the simple average of all the yields observed for that maturity since June 1964 till the preceding month. We define the unconditional yield curve at any date as the set of unconditional yields over all the maturities. Figure 1 below illustrates the unconditional yield curve for various dates. 


\section{INSERT FIGURE 1 HERE}

\section{$2.2 \quad$ Strategies}

We consider three classes of mean-reverting yield curve strategies, focusing on the three aspect of the yield curve: level, slope (i.e. yield spread) and curvature. For each strategy, the holding period of a trade is fixed at one month, after which a new trade is initiated. We impose the condition of cash neutrality, so that any excess cash is deposited at the 1-month tenor. Similarly, if additional funding is required, this is carried out at the 1-month tenor. As a bond of maturity $X$ months has a duration of $(X-1)$ months, the deposits and borrowings at the one-month tenor have no impact on the duration of each trade.

We allow for a 102-month training period in the construction of the unconditional yield curve, so that our calculation of the average payoff of each yieldcurve strategy starts from January 1973 to December 2000. A reason for the selection of the training period is the fact that the Lehman Brothers U.S. Government Intermediate Bond Index starts in January 1973.

\section{Class 1: Mean-reversion of yield levels}

This class of yield-curve trading strategies is based on the view that the level of the yield curve mean-reverts to the unconditional level. We consider two strategies.

\section{Strategy 1-A: Mean-reversion of average yield to the unconditional average}

This strategy takes the view that the average level of the yield curve meanreverts to that of the unconditional yield curve. In this trade, we compare the average of all the one-month forward yields at a particular date against the corresponding average 
for the unconditional yield curve. If the average interest rate level for the one-month forward yield curve is higher (lower) than the average for the unconditional yield curve, the expectation is that one-month forward yield curve would shift down (up). The implied strategy is to go long (short) all the bonds with maturities longer than one month. We consider two versions of the trade, one for maturities of only primary bonds, and another for all maturities, including all the interpolated maturities of the hypothetical bonds.

The trade is constructed as follows. If $k / 59$ dollars are invested in the 60 -month bond, with a duration of 59 months over the one-month holding period, the amount of cash invested in a bond of maturity of $X$ months, with duration of $(X-1)$ months, will be $k /(X-1)$ dollar. The funds required to invest in all the bonds are borrowed at the month tenor. Similarly, if the trade is to go short all the bonds, then the cash is deposited in the one-month tenor. Therefore, the strategy is a duration-weighted, cash neutral trade. In this strategy, a parallel shift in the yield curve generates approximately equal contribution to the payoff at each maturity.

\section{Strategy 1-B: Mean-reversion of yield at each maturity to its unconditional level}

This strategy is based on the view that the yield at each maturity mean-reverts to its unconditional level. In this trade, if the one-month forward yield is higher (lower) than the corresponding level on the unconditional yield curve, the expectation is that onemonth forward yield curve would fall (rise). Except for the one-month maturity, the implied strategy is to go long (short) the bond. The trade is constructed so that a parallel shift in the yield curve generates approximately equal contribution to the payoff at each maturity. If we go long or short $k / 59$ dollars in the 60 -month bond, the amount to long or short a bond of maturity of $X$ months, with duration of $(X-1)$ months will be $k /(X-1)$ dollar. Again, the one-month sector is where deposits and borrowings are made to 
achieve cash neutrality. We consider two versions of the trade, one for maturities of only primary bonds, and another for maturities, including all the interpolated maturities of the hypothetical bonds.

\section{Class 2: Mean-reversion of yield spreads}

In this strategy, the focus is on the mean reversion of the slope of the yield curve. Two versions of the trade are carried out.

Strategy 2-A: Mean-reversion of yield spread for the whole yield curve

The trade is constructed as follows. Consider the spread between the 59-month and 1-month maturities on the one-month forward yield curve, and compare it with that of the unconditional yield curve. If the one-month forward yield spread is larger (smaller) than the historical average, the expectation is that the slope of the yield curve would fall (rise). The implied strategy is to go long (short) the 60-month bond and go short (long) the 2-month bond.

The trade is constructed as follows. Suppose $k / 59$ dollars are invested in the 60month bond, we need to short the 2-month bond by $k$ dollars, to achieve durationmatching. The excess cash of $58 k / 59$ dollars is deposited in the one-month tenor. This strategy is a cash neutral trade and has a zero net duration. A parallel shift in the yield curve has negligible impact on the payoff.

\section{Strategy 2-B: Mean reversion of the yield spreads between 2 adjacent bonds.}

This trade is based on the view that the yield spread between two adjacent bonds of maturities $(X-1)$ months and $(Y-1)$ months, with $Y>X$, on the one-month forward yield curve would mean-revert to the corresponding spread on the unconditional yield curve. We compare the yield spread of adjacent pairs of bonds on the one-month forward yield curve against the historical average on the unconditional yield curve. If the one-month 
forward spread is larger (smaller) than that for the unconditional curve, go long the bond, with maturity of $Y$ months, and short the bond with maturity of $X$ months. We durationweight each leg of the trade so that changes in the yield spread with equal magnitude across different trades would generate approximately equal payoff contribution to the portfolio. For any bond with maturity of $Z$ months, the cash to go long or short the bond is $k /(Z-1)$ dollars. We again impose cash neutrality.

This trade essentially focuses on the slope of the yield curve for adjacent bonds on the one-month forward yield curve. We consider two versions of the trade, for both yield curves with only primary bonds and another set with maturities one month apart from one month to 60 months.

\section{Class 3: Mean reversion of curvature}

We define curvature as follows. Take three zero coupon bonds, with maturities of $X, Y$ and $Z$ months and corresponding one-month forward yields of $r_{X}, r_{Y}$ and $r_{Z}$. The curvature of the curve yield curve, as defined by the three bonds, is the measure:

$$
c(X, Y, Z) \equiv \frac{r_{Y}-r_{X}}{Y-X}-\frac{r_{Z}-r_{Y}}{Z-Y}
$$

If the curvature is smaller (larger) relative to the corresponding measure for the unconditional yield curve over the same set of maturities, the expectation is that the curvature of the one-month forward yield curve would increase (decrease). We consider two strategies.

\section{Strategy 3-A: Mean reversion of the curvature of the yield curve}

This strategy focuses on the entire yield curve. Specifically, we consider the maturities of 1-month, 29-month (a hypothetical bond, and the mid-point) and the 59month bond, on the one-month forward yield curve. If the curvature is expected to increase (decrease), the implied trade is to go long (short) the 2-month and 60-month 
bond and short (long) the 30-month bond, on the current yield curve. We match the durations of the various portions of the trade as follows. For every $k / 59$ dollars invested in the 60 -month bond (with a duration of 59 months), the amount invested in the 2-month bond is $k$ dollars. Next, for the 30-month bond (with a duration of 29 months), the amount to short is $2 k / 29$ dollars. The excess funding needs is met by borrowing $k(1 / 59+$ $1-2 k / 29)$ dollars at the one-month tenor. The trade is cash-neutral and has zero duration, so that a parallel shift in the yield curve or a change in the slope of the yield curve without a change in curvature has negligible impacts on the payoff. The curvature trading strategy we just described is often referred to as a barbell strategy.

Strategy 3-B: Mean reversion of the curvature of 3 adjacent bonds to the unconditional curvature

In this trade, we compare the curvature of any three adjacent bonds, say with maturities of $(X-1),(Y-1)$ and $(Z-1)$ months on the 1-month forward yield curve, as measured by $c(X-1, Y-1, Z-1)$ described in (2), with the corresponding curvature by the unconditional yield curve. If the curvature is smaller (larger) relative to that for the unconditional yield curve, the expectation is that the curvature of the current yield curve over the three maturities would increase (decrease). The implied trade is go long (short) the $X$-month and $Z$-month bond and short (long) the $Y$-month bond.

Again, we match the durations of the various portions of the trade so that the trade is immune to shifts in the yield curve. The amount of cash to be invested in the $X$ month and Z-month bonds are, respectively, $k /(X-1)$ dollars and $k /(Z-1)$ dollars. As for the bond with $Y$-month maturity, the cash amount is given by $2 k /(Y-1)$ dollars. The funding need or excess cash for this trade is $k /(X-1)+k /(Z-1)-2 k /(Y-1)$ dollars. The strategy is essentially a portfolio of curvature trades, using all the primary bonds. 
Since the hypothetical bonds are linearly interpolated from the primary bonds, the curvatures of the hypothetical bonds are zero. Hence, the trade does not work with hypothetical bonds.

\subsection{Benchmarks}

In order to be able to compare the performance of the mean-reverting trades described in the preceding subsection, we construct two benchmarks. The first is a fixed income strategy benchmark while the second is an equity investment benchmark.

Benchmark 1 - Investment in the Lehman Brothers U.S. Government Intermediate Bond Index ${ }^{4}$

This benchmark is constructed by assuming that we go long on the Lehman Brothers U.S. Government Intermediate Bond Index. The trade is funded by shorting 1month Treasury bills. This is a standard benchmark in the fixed income market, essentially deriving its returns from the term premium of interest rates (see Stigum and Fabozzi, 1987). This trade, like all the other strategies that we are testing, is cash neutral. When used as a benchmark, we will match the volatility of this strategy to the other strategies, and then compare the means.

4 There is a similar, though less common, benchmark that we can use. Profiting from the term premium involves buying a long-dated bond, and holding it for a period of time. Therefore, a logical benchmark is to simply buy a 60-month bond every month and holding it to maturity, all the while repeatedly funding the long positions with corresponding short positions in the 1-month Treasury Bills. A new 60-month bond is bought each month. Hence, at any one time, there is portfolio of bonds of maturities ranging from one month to 60 months. The payoff of the portfolio is calculated as the marked-to-market profits each month. As expected, this benchmark is almost identical to an investment in the Lehman Brothers U.S. Government Intermediate Bond Index. 


\section{Benchmark 2 - Cash-neutral Investment in S\&P Index}

Finally, we construct an equity benchmark to compare the performance of meanreverting trades against an alternative investment strategy in equity assets. Most studies on fixed income investment strategies do not compare the performance against the alternative strategy of investing in equity instruments. Any attempt at doing so often runs into problems of comparability, in terms of risk adjustments, holding period and credit risks etc. The equity benchmark we construct addresses these issues.

We use the S\&P index, starting from January 1973. Invest a dollar in the S\&P index, and borrow a dollar for one-month by shorting 1-month Treasury bills. The trade is cash-neutral, with a one-month holding period. We found that the average profit is $\$ 5.75$ for every $\$ 1000$ invested in the S\&P, funded by 1-month borrowings.

\section{Results and Analysis}

By adjusting the cash amounts, we can derive comparable volatilities (standard deviation) in payoffs for the S\&P investment against a particular mean-reverting yield curve strategy. Let the standard deviation of payoffs for the cash-neutral investment in the S\&P index from January 1973 to December 2000 be denoted $\sigma^{E}$. Similarly, let $\sigma^{\#}$ denote the standard deviation of payoffs, from January 1973 to December 2000, for a yield curve strategy numbered \#. Hence, to yield identical volatility in payoffs, the cash amount of $k$ dollars for a particular yield curve strategy is given by

$$
k=\frac{\sigma^{E}}{\sigma^{\#}}
$$

for each dollar invested in the S\&P trade. Note that the matching of volatilities across different strategies is done after all the payoffs are realized. This is to ensure that the volatilities of the 2 competing strategies will be matched exactly. This procedure does not, in any way, compromise the fact that all investment decisions are made "out-of-sample". 
It merely seeks to evaluate any two competing strategies on a fair and comparable basis by scaling the size of the monthly payoffs to match the standard deviations of the 2 strategies.

Table 1 below presents performance of the various strategies and benchmarks before accounting for trading costs. (We defer the discussion of transaction costs to Section 3.3.) From Table 1, we note that, on a comparable risk-adjusted basis, only strategies 2-B, 3-A and 3-B yield higher payoffs compared with the two benchmarks. In particular, not all mean-reverting yield curve strategies beat the simple buy-and-hold bonds strategy (Benchmark 1). In the following subsections, we analyze in detail the set of profitable mean-reverting yield-curve strategies.

INSERT TABLE 1 HERE

\subsection{Performance against the Benchmarks}

Against the two benchmarks, strategies 2-B and 3-B have performed remarkably well. On a comparable basis, Table 1 shows that the monthly payoff of strategy 2-B is about 5.1 times that of the monthly payoff of the equity benchmark (benchmark 2). This means that while investing $\$ 1000$ in S\&P (and funding the investment by shorting 1month Treasury Bills) generates an average profit of $\$ 5.75$ per month, strategy 2-B generates $\$ 29.51$ per month, after adjusting the volatility of payoffs for strategy 2-B to exactly match the volatility of payoffs from the S\&P strategy. For strategy 3-B, the corresponding ratio is about 3.3 times against the equity benchmark Hence, yield-spread mean-reverting and curvature mean-reverting strategies can outperform an equity investment strategy, on a risk-adjusted basis. 
Moreover, Strategies 2-B and 3-B also outperformed the bond benchmark. In the case of strategy 2-B, the average monthly payoff is about 5.9 times that of Benchmark 1, while for strategy 3-B, the average monthly payoff is about 3.8 times that of Benchmark 1.

The next subsection will test whether these superior performance of (gross) payoffs relative to the benchmarks are statistically significant.

\subsection{Test of Significance of Excess Payoffs against Benchmarks}

To test whether strategies $2-\mathrm{B}, 3-\mathrm{A}$ and $3-\mathrm{B}$ significantly outperform the benchmarks, we conduct two statistical tests of significance; these are: the paired t-test and the Diebold-Mariano statistical test (D-M test).

The paired t-test requires that the time-series of payoff differences be independent. Positive auto-correlations will incorrectly overstate the power of the test. Figures 2, 3 and 4 respectively plot the first 60 auto-correlation of the payoff differences between the strategies and the benchmarks. The autocorrelations are small in absolute values and are also distributed across positive and negative values. This means that the paired t-test, while not perfect, is still reasonable for our purpose.

INSERT FIGURES 2, 3 AND 4 HERE

The Diebold-Mariano statistic (see Diebold and Mariano, 1995) can be used to ascertain whether the mean of an autocorrelated series is significantly different from zero. It is less powerful that the t-test, but it requires weaker assumptions by accounting for auto-correlation. We implement the Diebold-Mariano statistic using a Barlett lag window 
(see Newey and West, 1987) to ensure non-negativity of the spectral density. We also allow autocorrelations of up to 60 lags. The Diebold-Mariano statistic is expressed as a Z-Score. Therefore, a number higher than 1.96 will imply that the difference between the two means being tested is statistically significant.

\section{INSERT TABLE 2 HERE}

Table 2 shows that while strategy 3-A does not significantly outperform the benchmarks, strategies 2-B and 3-B do. In particular, the p-value of the t-tests for strategies 2-B and 3$\mathrm{B}$ are negligible. For the D-M test, strategy 2-B managed a p-value of 0.0010 and 0.0013 against benchmarks 1 and 2 respectively. Meanwhile, strategy 3-B obtained a p-value of 0.0158 and 0.0258 against benchmarks 1 and 2 respectively. These p-values of these tests are so low, especially for strategy $2-\mathrm{B}$, that our results are still highly significant even after making simple bonferroni adjustments to account for the fact that we tested 6 strategies in this study. ${ }^{5}$

\subsection{Transaction Costs}

Thus far, all our analyses are done in terms of the gross payoffs of the different mean-reverting yield curve strategies. An obvious question to ask is whether the set of profitable trades, specifically strategies $2-\mathrm{B}$ and $3-\mathrm{B}$, would continue to outperform the indices (or even yield positive returns) when the appropriate transaction costs are taken

\footnotetext{
${ }^{5}$ The simple bonferroni correction adjusts the required $\mathrm{p}$-value for rejection to account for multiple tests by dividing the alpha-level by the number of tests conducted. Therefore, in the case of our study where 6 tests are conducted, the p-value required for a rejection at the $5 \%$ level is 0.008333 . The p-value from Strategy 2-B is still smaller than 0.00833 .
} 
into account. Transaction costs in bond trading are embedded in the form of the spread between the 'bid' and 'ask' yields. The 5-year average spreads are approximately 1 basis point for Treasury bills that mature in 1 year or less, 0.8 basis points for 2-year bonds and 0.35 basis points for 5 -year bonds ${ }^{6}$. A reasonable assumption would be that the transaction cost for each trade is half the quoted spread. For the purpose of this paper, we assume a spread of 1 basis point for all the bonds traded (and therefore pay a transaction cost of half basis point). Assuming a cost of half basis point, the cost expressed in dollars is a function of the maturity of the bond and the value of the bond, and can be approximated as follows:

$$
(\text { Transaction Cost }) \approx 0.00005 *(\text { Maturity in Years }) *(\text { Value of Bond })
$$

As an illustration, buying or selling $\$ 100,000,000$ worth of 6-month Treasury Bills will attract a transaction cost of $0.00005^{*} 0.5 * \$ 100,000,000=\$ 2500$.

INSERT TABLE 3 HERE

The profitability of strategies 2-B, 3-A and 3-B after accounting for transaction costs are reported in Table 3 . We assume that the benchmarks are traded without any transaction costs. Strategy $2-B$ is still significantly more profitable than both the benchmarks under all measures (both the t-tests and the D-M tests). Strategy 3-B is only significantly better than the benchmarks in the t-tests but not in the D-M tests, while Strategy 3-A remains marginally better than the benchmarks.

It is important to note that the transaction costs we calculated are based on the assumption that the mean-reverting yield curve strategies are executed on a physical basis,

\footnotetext{
${ }^{6}$ Source: Bloomberg, accessed on 5 November 2003.
} 
i.e. the actual bonds are bought and sold and funds are borrowed (if required) to construct the trades on a monthly basis. The transaction costs can be diminished by reducing the frequency of the entering and exiting trades. For instance, instead of executing the trades on a monthly basis, the trades could be executed on a quarterly basis, or when the relevant deviations on forward yield curves for spreads and curvatures exceed certain thresholds.

More importantly, the transaction costs can be reduced substantially if the yield curve strategies are structured as derivative trades (on a notional basis) to mirror the economic cashflows of the underlying strategies, without actually funding and holding the bonds. These derivative trades are commonly carried out in the fixed income market. ${ }^{7}$

Therefore, while factoring in transaction costs may appear to diminish the profits from some the mean-reverting yield curve trades, there are different ways to lower the transaction costs. Nevertheless, Strategy 2-B still returns a significantly better profit than all the benchmarks even after accounting for these costs.

\subsection{Value-Add of Mean-Reverting Strategy to Investment in the S\&P Index}

In the preceding sections, we have shown that a number of mean-reverting yieldcurve strategies can be highly profitable. Another way to demonstrate the attractiveness of mean-reverting yield curve strategies is to consider the incremental value-add of including such strategies to an existing investment strategy. In this regard, Foster and Stine (2003) introduce a convenient test to ascertain whether a particular strategy can add

7 Of course, the pricing of the derivative trades may involve other costs as well, as investment banks take a cut from the potential profits. Fortunately, there are some standard derivatives that can be traded at extremely low cost and can substitute for a pair of long-short trade in bonds. For instance, the highly liquid Eurodollar futures gives identical payoff as shorting a bond of a certain maturity, and at the same time going long a another bond of maturity 90 days longer than the shorted bond. 
value to a buy-and-hold investment in the S\&P index. The Foster-Stine test involves regressing the excess returns of the selected strategy against the excess returns from the buy-and-hold investment in the S\&P index. Based on this regression, we can obtain the t-statistic as well as the p-value of the intercept that allows us to test if adding a new strategy leads to a significant improvement in the performance of the portfolio. Again, the p-value needs to be adjusted using the bonferonni correction when multiple strategies are tested. If the regression intercept is statistically significant, then we can say that the particular strategy does in fact add value to the original strategy of buy-and-hold the S\&P index. The basic premise behind this test is that a strategy that gives a positive mean return and is not too highly correlated to the S\&P index can be linearly combined with the $\mathrm{S} \& \mathrm{P}$ index to obtain a better mean-variance return profile. In other words, a strategy that serves as a good addition to diversify holdings in the S\&P index can therefore add value.

In the case of the mean-reverting yield-curve strategies we examined in this paper, Strategies 2-B, 3-A and 3-B are found to have significant value-add even after accounting for transaction costs and the bonferonni correction. In particular, Strategies 2-B and 3-B have t-statistics of 9.1758 and 4.9836 respectively, with negligible corresponding p-values. The results of the Foster-Stine test are reported in Table 4 below.

INSERT TABLE 4 HERE

\subsection{Breakdown of the Payoffs}

For strategies 2-B and 3-B, we further analyzed the breakdown of payoffs. Figures 5 and 6 show the contribution of the payoffs from each trade trade-segment in the portfolio for Strategies 2-B and 3-B, respectively. 


\section{INSERT FIGURES 5 AND 6 HERE}

The results show that almost every trade in the portfolio contributed positively to the payoffs. No single trade dominates the entire portfolio, although interestingly, trading the yield spread between 10-month and 11-month maturities as well as trading on the curvature among 10-month, 11-month and 23-month maturities, on the one-month forward yield curve, generate substantial profits. For these two yield curve strategies, we plot the monthly payoffs against the absolute deviations of the relevant parameter from the unconditional yield curve. The plots are shown in Figures 7 and 8 below.

INSERT FIGURES 7 AND 8 HERE

The figures show that, for these two trades, the monthly payoffs have a high positive correlation with the absolute deviations from the unconditional yield curve ( correlation $=0.814$ for strategy $2-\mathrm{B}$, and correlation $=0.763$ for strategy $3-\mathrm{B}) . \quad$ In other words, the payoffs from these two trades are not random payoffs: the larger the deviation from the unconditional yield curve, the larger the resulting profit from that particular trade. This result strongly supports the view that the spread and curvature of these portions of the yield-curve do in fact mean-revert.

The presence of the most profitable trade segments in the 10-month to 23 month portion of the one-month forward yield curve provides some support for the "marketsegmentation" view of the interest rate term structure in the fixed income market. This is 
the market view that many participants in the fixed income market have preferred habitats that are dictated by the nature of liabilities and investments, so that a major factor influencing the shape of the yield curve is the asset-liability management constraints that are either regulatory or self-imposed. Specifically, the yield curve is viewed as comprising a "short-end" - up to the 12-month maturity - and a "long-end" from 12-month onwards. Asset-liability management constraints, when they exist, restrict lenders and borrowers to the short-end or the long-end of the yield curve, or even certain specific maturity sectors, and, as a result, investors and borrowers do not shift from one maturity sector to another to take advantage of opportunities arising from differences between market expectations and the forward interest rates. Arbitrage trades in the fixed income market are frequently constructed in the transition between the shortend and the long-end of the yield curves.

\subsection{Time Series Analysis}

To investigate the profitability of strategies $2-\mathrm{B}$ and 3 -B over time, we plot the 10-year moving average of the payoffs of strategies 2-B and 3-B against the two benchmarks. These are shown in Figures 9 and 10 below.

INSERT FIGURES 9 AND 10 HERE

From Figures 9 and 10, it can be seen that the average monthly payoffs for both strategies $2-\mathrm{B}$ and 3-B were initially significantly higher than the payoffs for the two benchmarks. However, the gaps against the two benchmarks appeared to have narrowed. In the case of strategy 3-B, the gap narrowed sharply from around 1984 onwards, and by 1990, the 10-year moving average monthly return has fallen below the two benchmarks. 
A plausible explanation of this finding is that fixed income market has improved in efficiency over the years, as market information improved and trading liquidity increased. Moreover, improvements in computing technology and telecommunications also allowed traders to rapidly seek out and take advantage of trading opportunities afforded by the yield-curve mean-reversion market view.

\section{Conclusion}

The objective of this paper is to examine the profitability of a class of yield-curve trading strategies that are based on the view that the yield curve mean-reverts to an unconditional yield curve. Our study has shown that a number of these yield-curve trading strategies can be highly profitable. In particular, trading strategies focusing on the mean-reversion of the yield spreads and curvatures significantly outperformed two commonly-used benchmarks of investing in the Lehman Brothers U.S. Government Intermediate Bond Index and investing in the S\&P, on a risk-adjusted basis. Although factoring in transaction costs lower the profitability of these trades against the benchmarks, the significant result still remains for some of these strategies. Transaction costs can also be reduced substantially, for instance, through structured derivative trades that mirror the underlying cashflows or by reducing the frequency of the trades.

We also investigated the profitability of these mean-reverting yield curve trades over time. A time series analysis of the performance of the various yield-curve trading strategies also show that market efficiency appeared to have improved considerably, and the scope for excess returns over the benchmarks has diminished. Nonetheless, trading opportunities still exist in yield-spread mean-reversion strategies. Moreover, these strategies are found to have significant value-add to a strategy of buy-and-hold the S\&P index. 


\section{References}

Balduzzi, P., Bertola, G., and Foresi, S., 1997. A model of target changes and the term structure of interest rates. Journal of Monetary Economics 24, 371-399.

Campbell, J., 1995. Some lessons from the yield curve. Journal of Economic Perspectives 9, 129-152.

Campbell, J., Shiller, R.J., 1991. Yield spreads and interest rate movements: A bird's eye view. Review of Economic Studies 58, 495-514.

Culbertson, J.M., 1957. The term structure of interest rates. Quarterly Journal of Economics 71, 485-517.

Cox, J.C., Ingersoll, J.E., Ross, S.A., 1981. A reexamination of traditional hypotheses about the term structure of interest rates. Journal of Finance 36, 769-799.

Cox, J.C., Ingersoll, J.E., Ross, S.A., 1985. A theory of the term structure of interest rates. Econometrica 53, 385-407.

Darst, D.M. , 1975. The Complete Bond Book, McGraw Hill, New York.

De Leonardis, N.J., 1966. Opportunities for increasing earnings on short-term investments, Financial Executive, 10, 48:53.

Diebold, F., Mariano, R.S., 1995. Comparing predictive accuracy” Journal of Business Economics and Statistics, 13, 253-263.

Drakos, K., 2001. Fixed income excess returns and time to maturity. International Review of Financial Analysis 10, 431-442.

Dyl, E.A., Joehnk, M.D., 1981. Riding the yield curve: does it work? Journal of Portfolio Management 7, 13-17.

Fabozzi, F. J., 1996. Bond Markets, Analysis and Strategies. Upper Saddle River, Prentice Hall, New Jersey.

Fisher, I., 1896. Appreciation and Interest. Publications of the American Economic Association 9, 331-442.

Fisher, M., 2001. Forces that shape the yield curve: Parts 1 and 2. Working paper 20013, Federal Reserve Bank of Atlanta, USA.

Foster, D.P., Stine, R.A., 2003. Ponzironi Returns: How to distinguish a "con" from a good investment using only statistics. Working paper 2003, The Wharton School, University of Pennsylvania.

Freund, W.C., 1970. Investment fundamentals. The American Bankers Association, 9, $331-442$.

Grieves, R., Marchus, A.J., 1992. Riding the yield curve reprise. Journal of Portfolio Management 18, 67-76.

Hamburger, M.J., Platt, E.N., 1975. The expectations hypothesis and the efficiency of the Treasury bill market. Review of Economics and Statistics 57, 190-199.

Jones, F.J., 1991. Yield curve strategies. Journal of Fixed Income, 43-51.

Litterman, R., Scheinkman, J., 1991. Common factors affecting the bond returns, Journal of Fixed Income, 1, 54-61.

Lutz, F.A., 1940. The Structure of Interest Rates. Quarterly Journal of Economics 40, 36-63. 
Mankiw, G., Miron, J., 1986. The changing behavior of the term structure of interest rates. Quarterly Journal of Economics 101, 211-228.

Mann, S. V., Ramanlal, P., 1997. The relative performance of yield curve strategies. Journal of Portfolio Management 23 (4), 64-70.

Meiselman, D., 1962. The Term Structure of Interest Rates. Englewood Cliffs, Prentice Hall.

Newey, W., West, K. 1987. A simple, positive-semi definite, heteroskedasticity and autocorrelation consistent covariance matrix. Econometrica, 55, 703-708.

Pelaez, R.F., 1997. Riding the yield curve: Term premiums and excess returns. Review of Financial Economics 6 91): 113-119.

Rudebusch, G., Federal Reserve interest rate targeting, rational expectations, and the term structure. Journal of Monetary Economics 5, 133-143.

Shiller, R.J., 1990. The term structure of interest rates. In Friedman, B., Hahn, F. (ed) The Handbook of Monetary Economics, North Holland.

Shiller, R.J., Campbell, J., Schoenholtz, K., 1983. Forward rates and future policy: Interpreting the term structure of interest rates, Brookings Papers on Economic Activity 1, 173-217.

Stigum, M., Fabozzi, F., 1987. The Dow Jones-Irwin Guide to Bond and Money Market Investments. Homewood, IL: Dow Jones-Irwin.

Vasicek, O., 1977. An equilibrium characterization of the Term Structure. Journal of Financial Economics, 5, 177-188.

Weberman, B., 1976. Playing the yield curve, Forbes, August 15, 90-101. 
Table 1

Risk-adjusted Average Gross Payoff of Mean-Reverting Yield-Curve Strategies ${ }^{1}$

\begin{tabular}{|c|c|c|c|c|c|}
\hline Class & Strategy & Bonds2 & Mean Payoff & $\begin{array}{c}\text { Against } \\
\text { Benchmark 1 }\end{array}$ & $\begin{array}{c}\text { Against } \\
\text { Benchmark 2 }\end{array}$ \\
\hline Yield Level & 1-A & $\mathrm{P}$ & 0.00228 & 0.454 & 0.397 \\
\hline & 1-B & $\mathrm{H}$ & 0.00159 & 0.317 & 0.277 \\
\hline & 2-A & $\mathrm{P}$ & 0.00257 & 0.512 & 0.447 \\
\hline Yield Spread & 2-B & $\mathrm{P}$ & 0.00183 & 0.365 & 0.233 \\
\hline & & $\mathrm{H}$ & 0.02951 & 5.878 & 5.132 \\
\hline Curvature & 3-A & $\mathrm{P}$ & 0.01025 & 2.042 & 1.783 \\
\hline & 3-B & $\mathrm{P}$ & 0.01917 & 3.819 & 3.334 \\
\hline \multirow{2}{*}{ Benchmark 1 } & $\begin{array}{c}\text { Investment in LB } \\
\text { Government }\end{array}$ & & 0.00502 & 1.000 & 0.873 \\
\hline Benchmark 2 & Investment in S\&P Index & & 0.00575 & 1.145 & 1.000 \\
\hline
\end{tabular}

Notes:

1. The average payoffs are risk-adjusted. For each dollar invested in the S\&P index (funded by borrowing 1-month), the amount invested in a yield-curve trade is scaled to give the same standard deviation of the payoffs from Jan 1973 to December 2000.

2. $\quad \mathrm{P}$ - the trade is structured for primary bonds only; $\mathrm{H}$ - the trade is structured for both primary and hypothetical bonds. 
Table 2

Significance Tests of Excess Payoffs of Strategies with respect to Benchmarks

\begin{tabular}{|c|c|c|c|c|c|c|c|}
\hline \multirow{2}{*}{} & \multicolumn{5}{c|}{ Strategy } \\
\cline { 3 - 8 } & \multicolumn{2}{|c|}{$2-B^{1}$} & \multicolumn{2}{c|}{3 -A } & \multicolumn{2}{c|}{3 -B } \\
\hline \multirow{2}{*}{ Mean Payoff } & \multicolumn{2}{|c|}{0.02851} & \multicolumn{2}{c|}{0.01025} & \multicolumn{2}{c|}{0.01917} \\
\hline \multirow{4}{*}{ t-test } & Statistic & p-value & Statistic & p-value & Statistic & p-value \\
\cline { 2 - 8 } & vs zero profits & 11.8154 & 0.0000 & 4.2466 & 0.0000 & 7.9442 & 0.0000 \\
\cline { 2 - 8 } & vs Benchmark 1 & 6.9762 & 0.0000 & 1.4056 & 0.1608 & 4.2203 & 0.0000 \\
\cline { 2 - 8 } & vs Benchmark 2 & 6.8820 & 0.0000 & 1.3372 & 0.1821 & 4.0078 & 0.0000 \\
\hline \multirow{3}{*}{ D-M test } & vs zero profits & 5.0996 & 0.0000 & 2.3661 & 0.0180 & 3.9423 & 0.0000 \\
\cline { 2 - 8 } & vs Benchmark 1 & 3.3009 & 0.0010 & 0.8205 & 0.4119 & 2.4130 & 0.0158 \\
\cline { 2 - 8 } & vs Benchmark 2 & 3.2087 & 0.0013 & 0.7876 & 0.4309 & 2.2287 & 0.0258 \\
\hline
\end{tabular}

Note:

1. We are reporting the significance tests for the trade structured with primary bonds only. The results of the significance tests for strategy 2-B using the trade structured for both primary and hypothetical bonds are essentially identical. 
Table 3

Significance Tests of Excess Payoffs of Strategies, net of transaction costs with respect to Benchmarks

\begin{tabular}{|c|c|c|c|c|c|c|c|}
\hline \multirow{2}{*}{} & \multicolumn{3}{c|}{ Strategy } \\
\cline { 3 - 8 } \multicolumn{2}{|c|}{} & \multicolumn{2}{|c|}{2 -B } & \multicolumn{2}{c|}{3 -A } & \multicolumn{2}{c|}{3 -B } \\
\hline \multirow{2}{*}{ Mean Payoff } & \multicolumn{2}{|c|}{0.02267} & \multicolumn{2}{c|}{0.00701} & \multicolumn{2}{c|}{0.01234} \\
\hline \multirow{4}{*}{ t-test } & Statistic & p-value & Statistic & p-value & Statistic & p-value \\
\cline { 2 - 8 } & vs zero profits & 9.3923 & 0.0000 & 2.9046 & 0.0039 & 5.1130 & 0.0000 \\
\cline { 2 - 8 } & vs Benchmark 1 & 5.2324 & 0.0000 & 0.5356 & 0.5926 & 2.1845 & 0.0296 \\
\hline \multirow{3}{*}{$\begin{array}{c}\text { D-M } \\
\text { test }\end{array}$} & vs Benchmark 2 & 5.1113 & 0.0000 & 0.3748 & 0.7081 & 1.9655 & 0.0502 \\
\cline { 2 - 8 } & vs zero profits & 4.2509 & 0.0000 & 1.6160 & 0.1061 & 2.5877 & 0.0097 \\
\cline { 2 - 8 } & vs Benchmark 1 & 2.5691 & 0.0102 & 0.3125 & 0.7547 & 1.2703 & 0.2040 \\
\cline { 2 - 8 } & vs Benchmark 2 & 2.4715 & 0.0135 & 0.2207 & 0.8253 & 1.1136 & 0.2655 \\
\hline
\end{tabular}

Notes:

1. This table lists the breakeven transaction costs that will render the average profits of the strategies to exactly equal that of the benchmark.

2. We are assuming that the benchmarks are traded with zero transaction cost. 
Table 4

Test of Value-Added of Mean-Reverting Strategies to a Buy-and-Hold Investment in the S\&P Index

\begin{tabular}{|c|c|c|c|c|c|c|}
\hline \multirow{2}{*}{} & \multicolumn{5}{|c|}{ Strategy } \\
\cline { 2 - 7 } & \multicolumn{2}{|c|}{$2-\mathrm{B}$} & \multicolumn{2}{c|}{ 3-A } & \multicolumn{2}{c|}{ 3-B } \\
\hline & t-stat & p-value & t-stat & p-value & t-stat & p-value \\
\hline alpha & 9.1758 & 0.0000 & 2.8106 & 0.0052 & 4.9836 & 0.0000 \\
\hline
\end{tabular}

Notes:

1. This table lists the usefulness of each strategy when it is added to one that buys-andholds the S\&P index (refer to Foster and Stine, 2003).

2. Excess return of the strategy $(\mathrm{Y})$ is regressed on the excess return of the S\&P index (X). If the t-stat of the intercept is significantly positive, this will imply that the particular strategy can add value to a simple buy-and-hold S\&P strategy. 
Figure 1

Unconditional Zero-Coupon Yield Curve

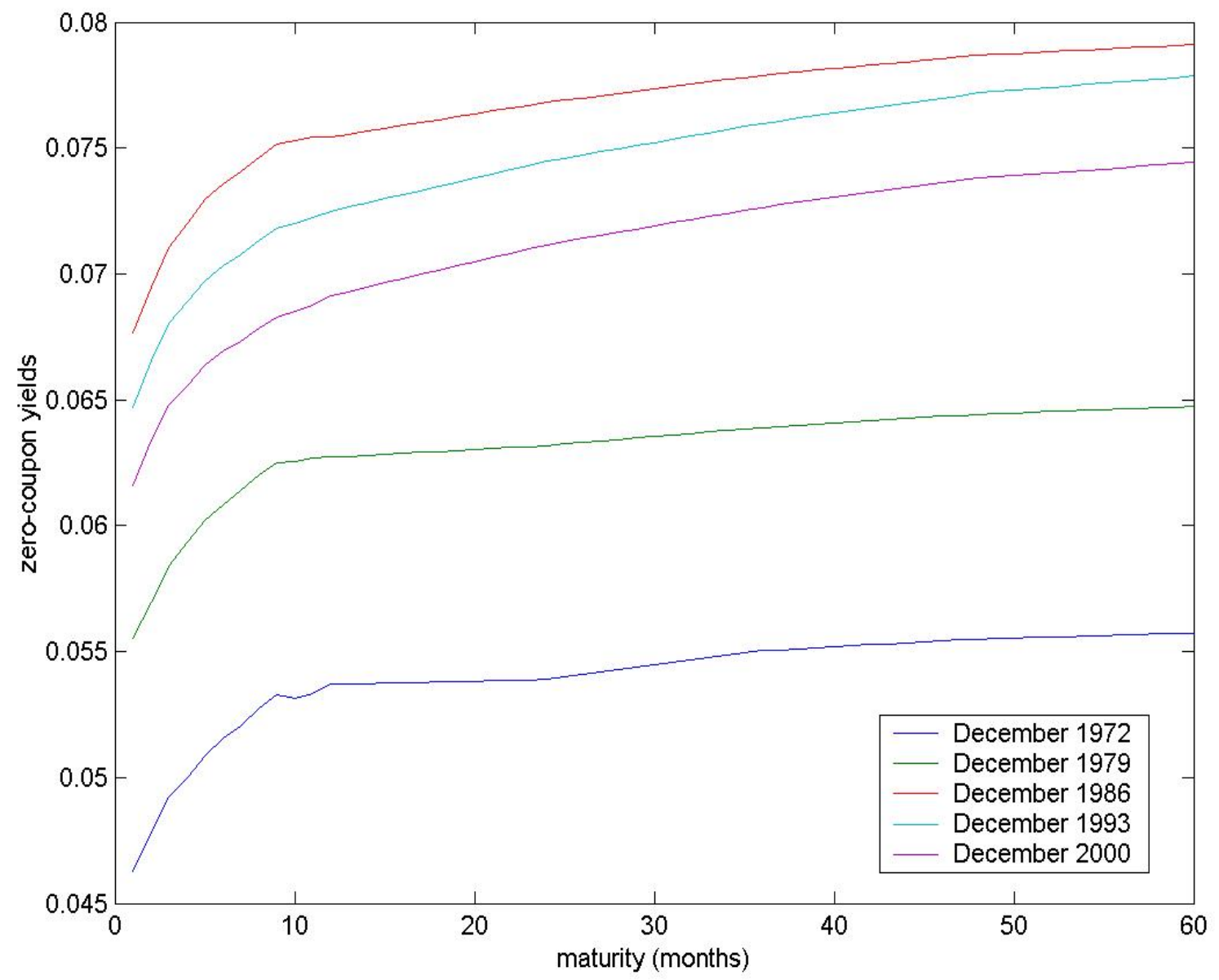


Figure 2

Autocorrelations of Strategy 2-B Against Benchmarks

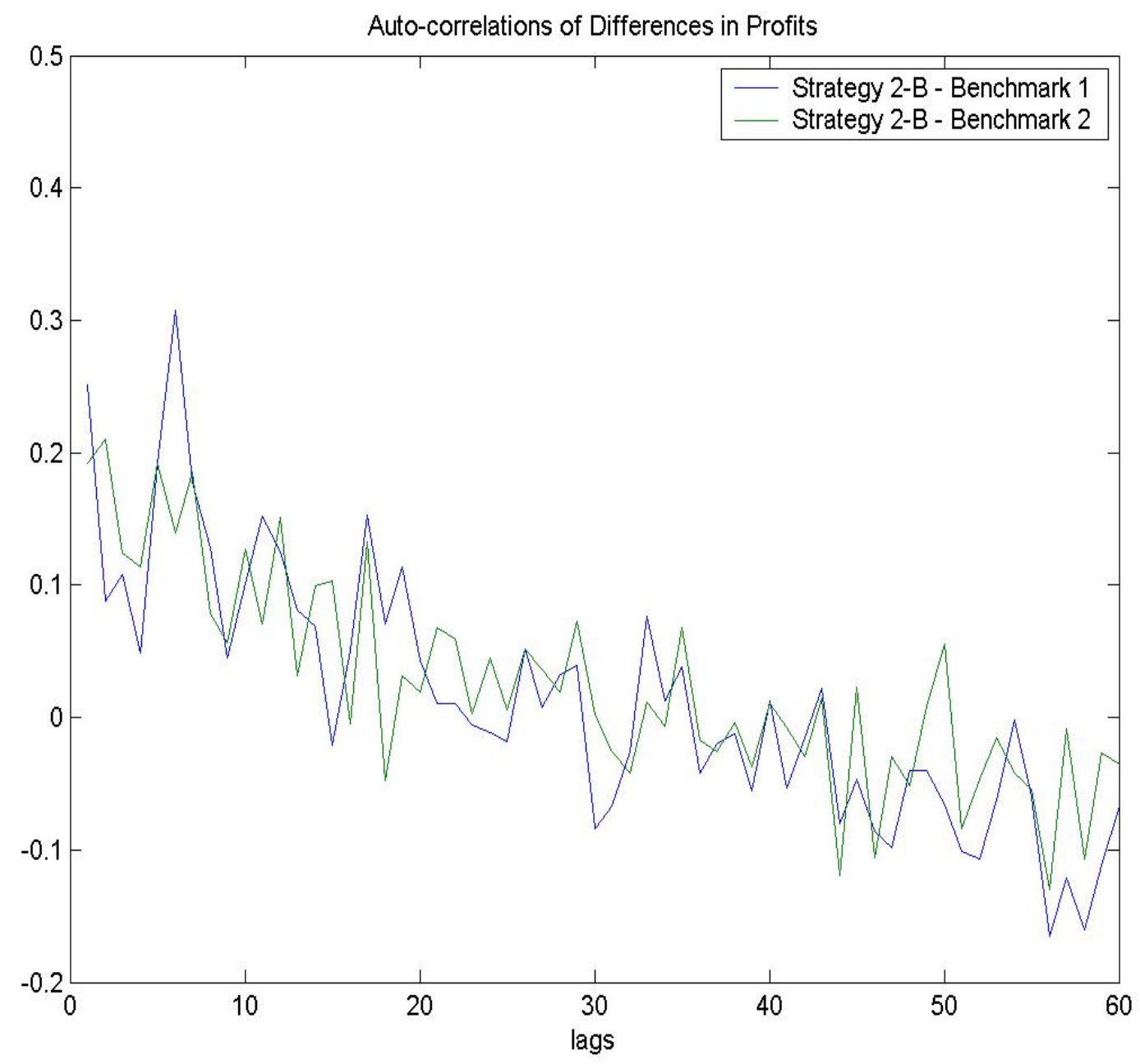


Figure 3

Autocorrelations of Strategy 3-A Against Benchmarks

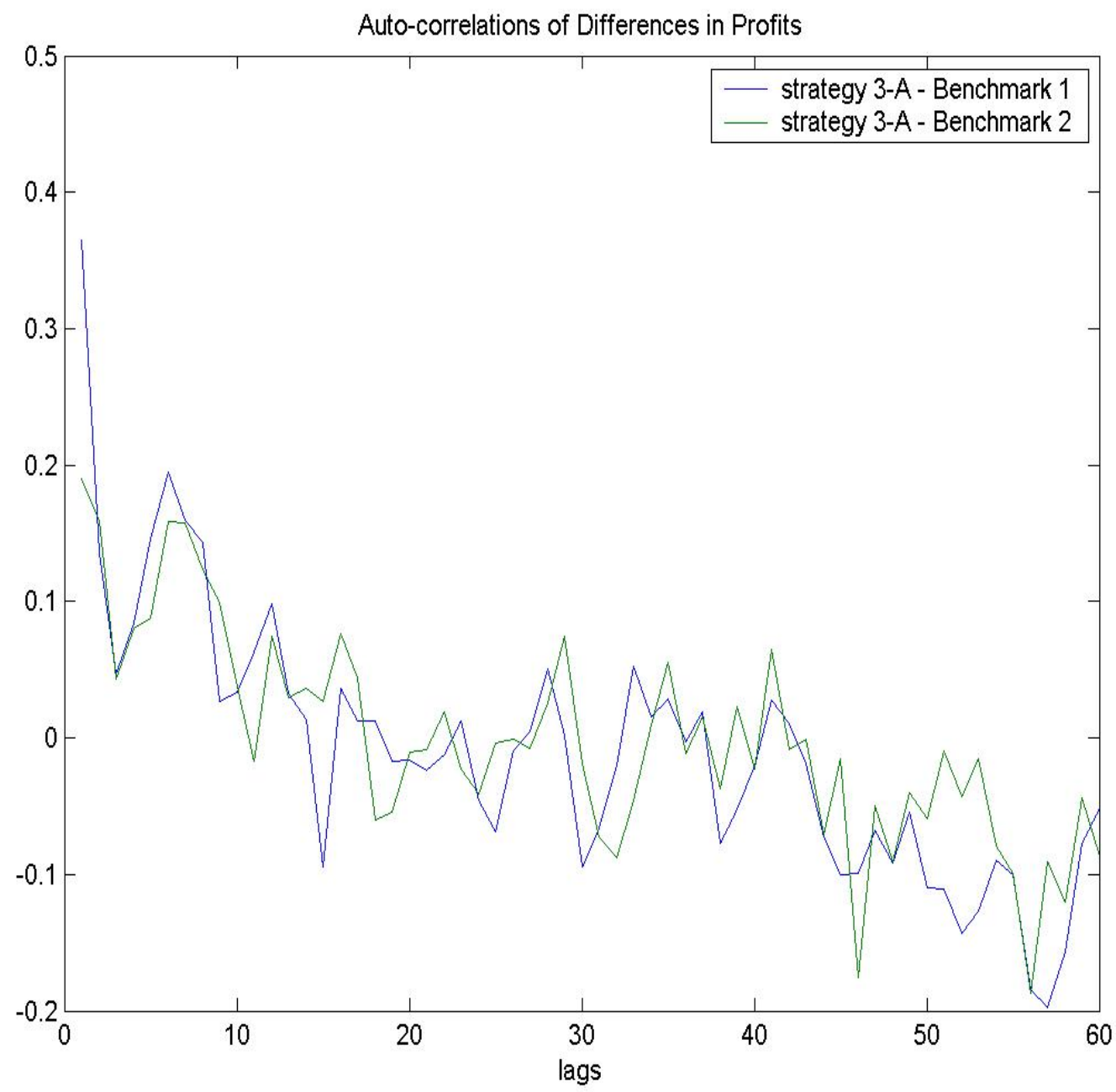


Figure 4

Autocorrelations of Strategy 3-B Against Benchmarks

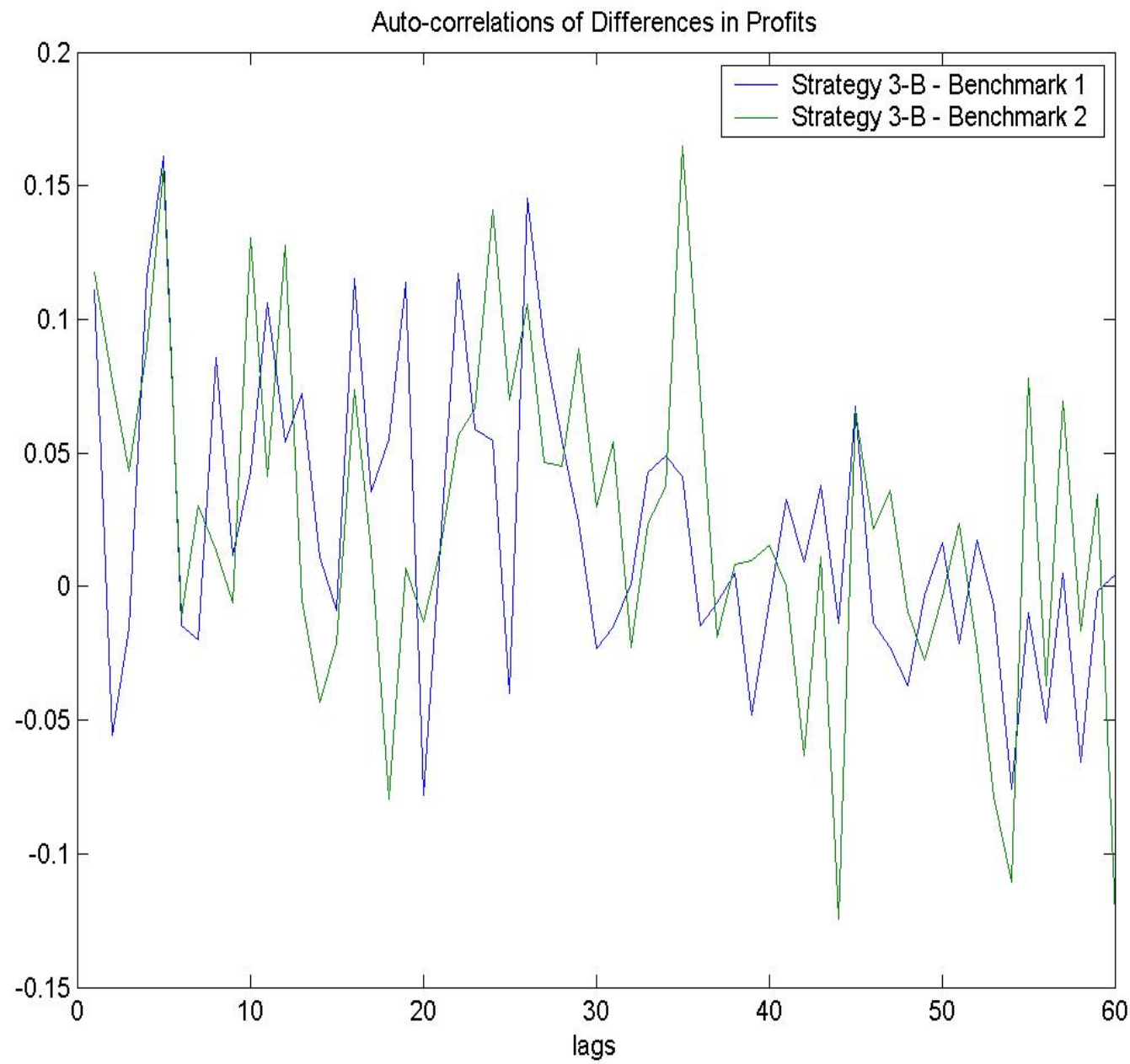


Figure 5

Contribution of Different Trades to the Payoff of Strategy 2-B (Primary Bonds)

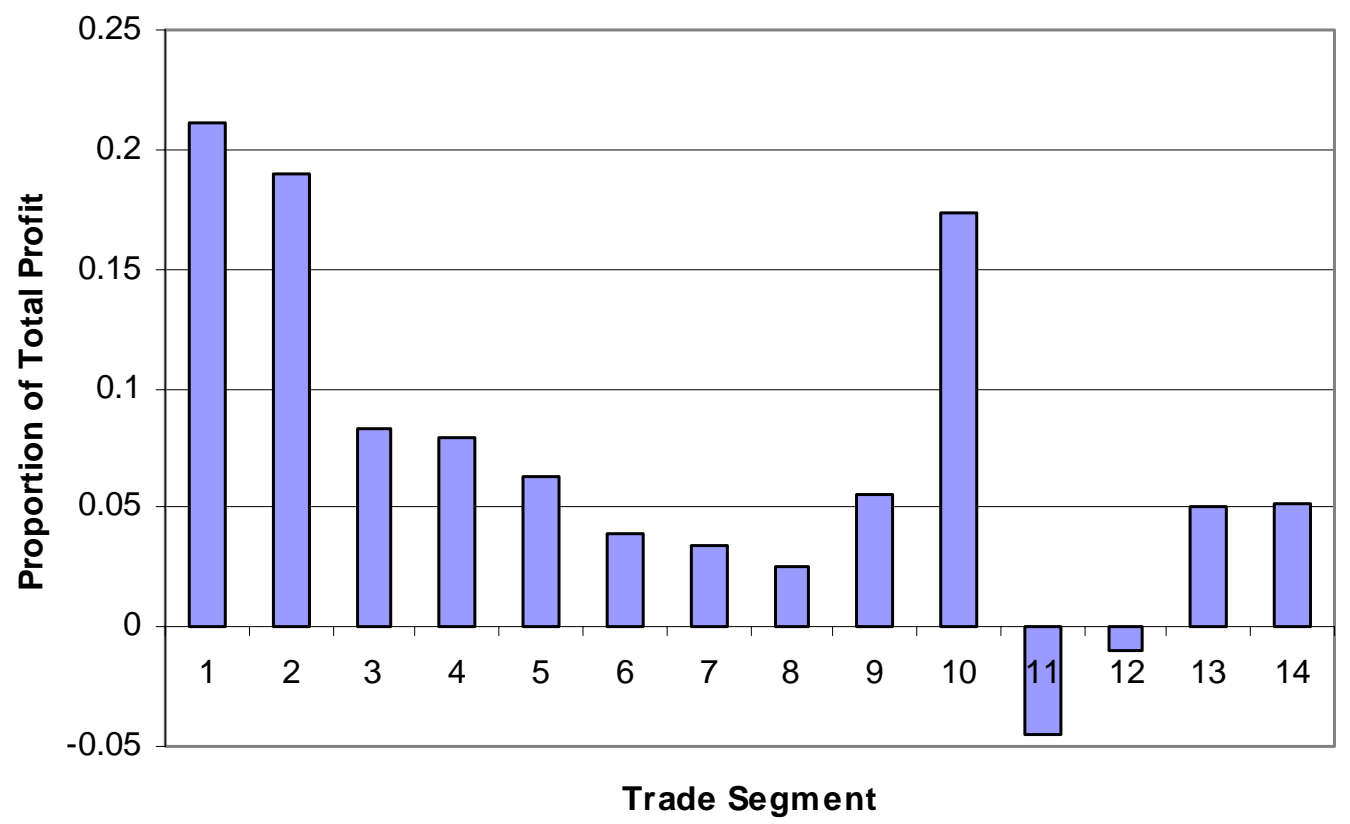

Trade segments of Strategy 2-B: Yield spread mean-reversion trade, on the 1-month forward curve

1. 1-2 month spread

2. 2-3 month spread

3 . 3-4 month spread

4. 4-5 month spread

5 . 5-6 month spread

6. 6-7 month spread

$7 . \quad 7-8$ month spread

$8 . \quad 8-9$ month spread

9. $9-10$ month spread

10. 10-11 month spread

11. 11-23 month spread

12. 23-35 month spread

13. 35-47 month spread

14. 47-59 month spread 
Figure 6

Contribution of Different Trades to the Payoff of Strategy 3-B (Primary Bonds)

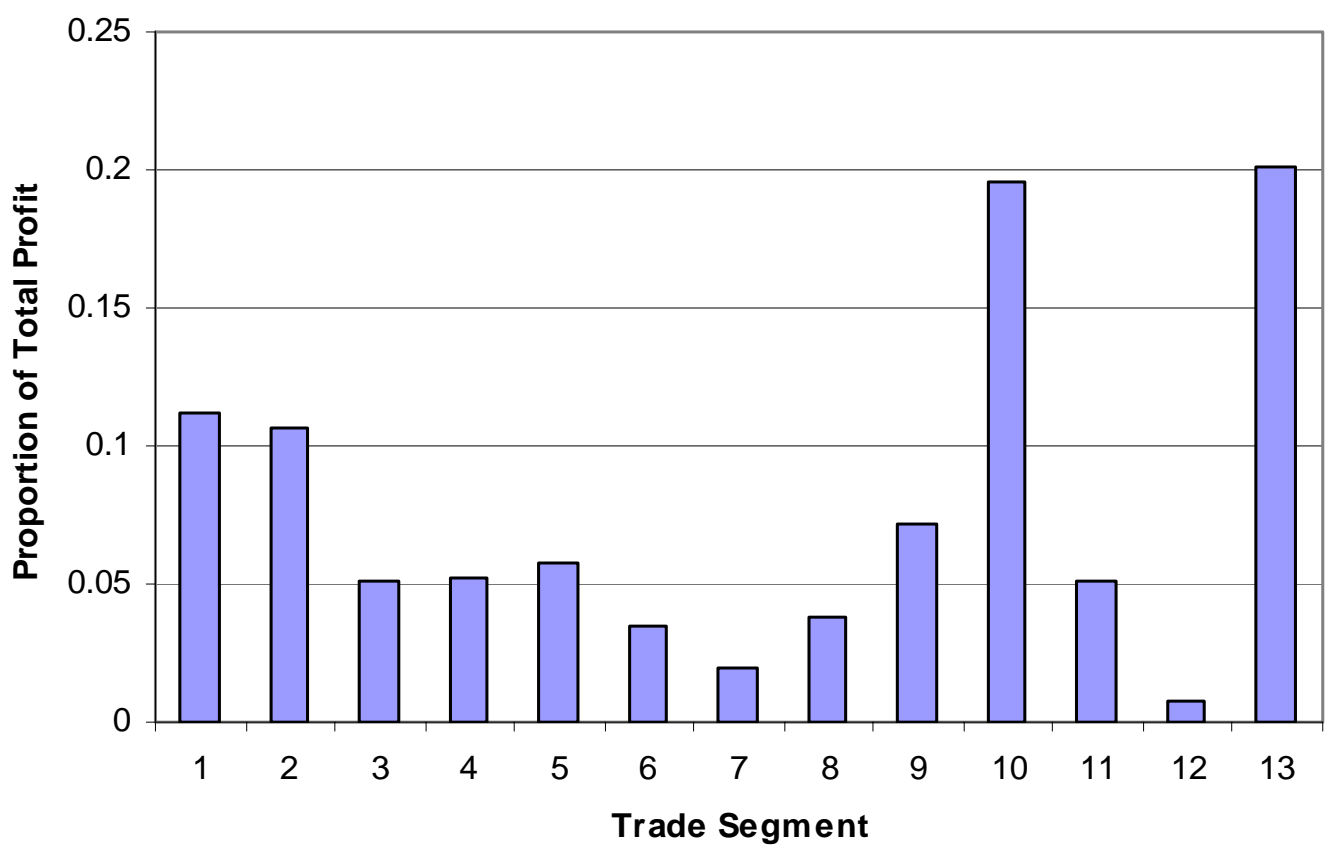

Trade segments of Strategy 3-B: Curvature mean-reversion trade, on the one-month forward curve

1. 1-2-3 month curvature

2. 2-3-4 month curvature

3. 3-4-5 month curvature

4. $\quad$ 4-5-6 month curvature

$5 . \quad 5-6-7$ month curvature

6. 6-7-8 month curvature

$7 . \quad 7-8-9$ month curvature

$8 . \quad 8-9-10$ month curvature

9. 9-10-11 month curvature

10. 10-11-23 month curvature

11. 11-23-35 month curvature

12. 23-35-47 month curvature

13. 35-47-59 month curvature 
Figure 7

10-11 month Yield Spread Trade of Strategy 2-B, on the one-month forward curve

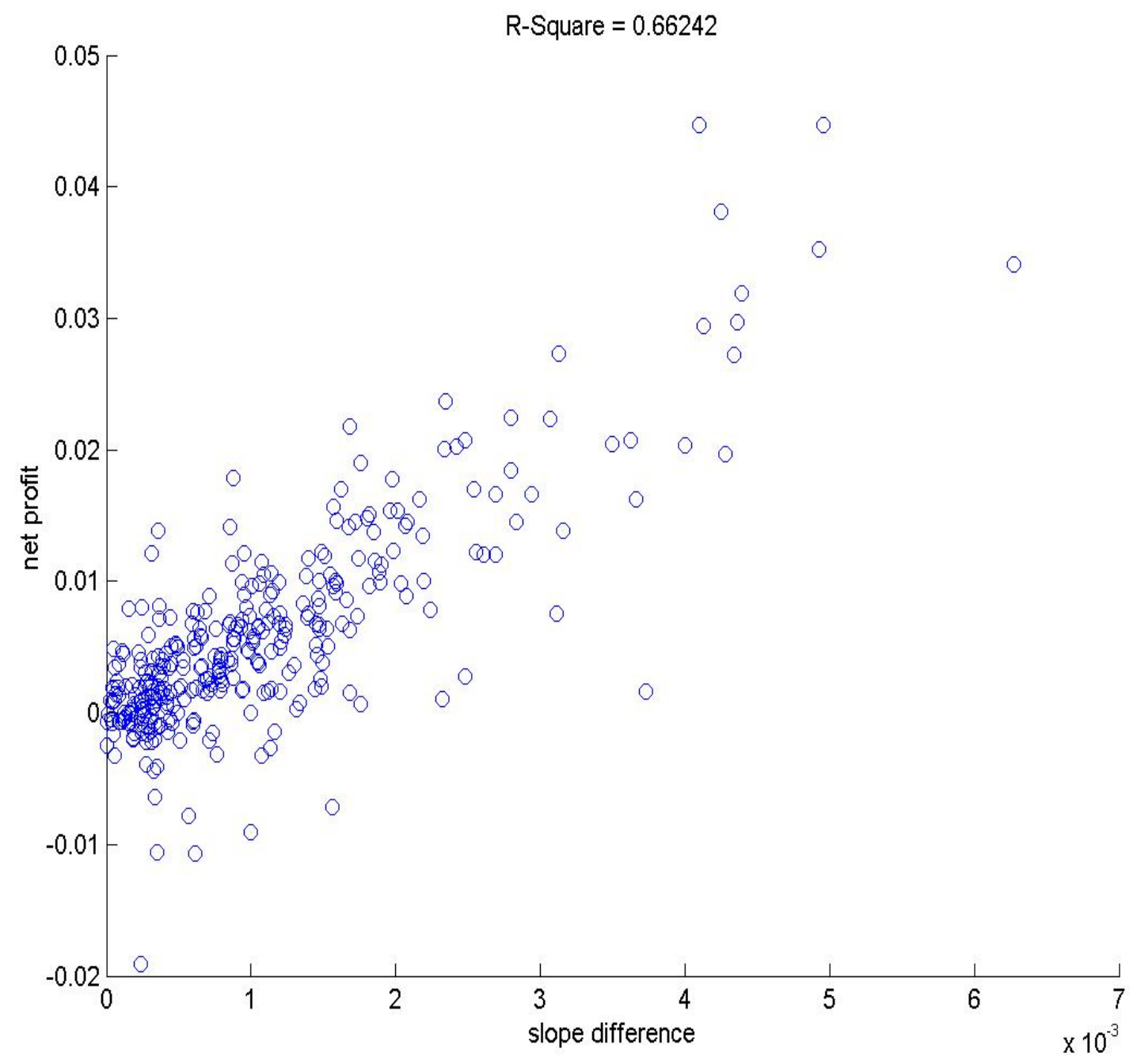


Figure 8

9-10-11 month Curvature Trade of Strategy 3-B, on the one-month forward curve

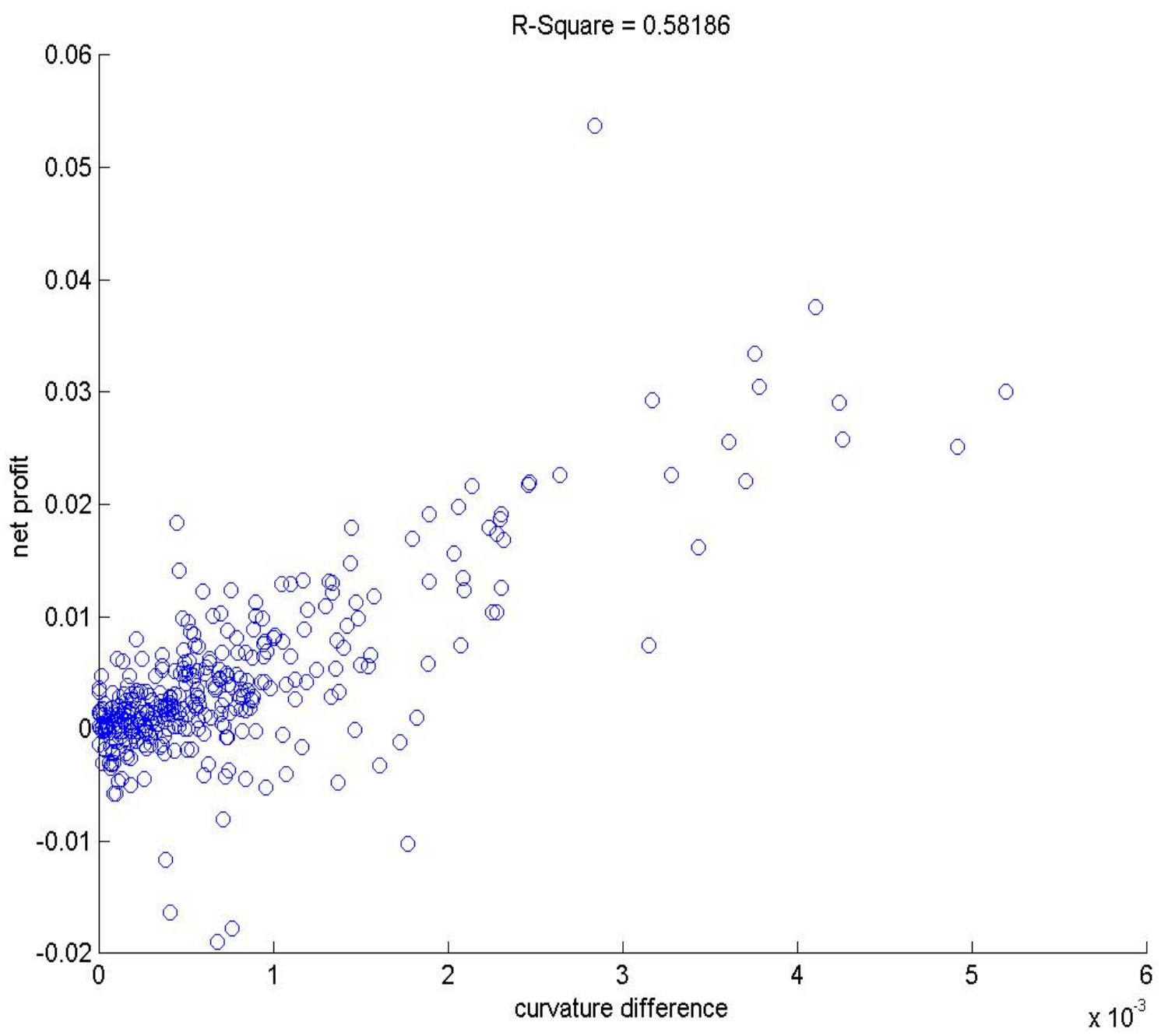


Figure 9

10-year Moving Average of Monthly Payoffs of Strategy 2-B

(for all Bonds)

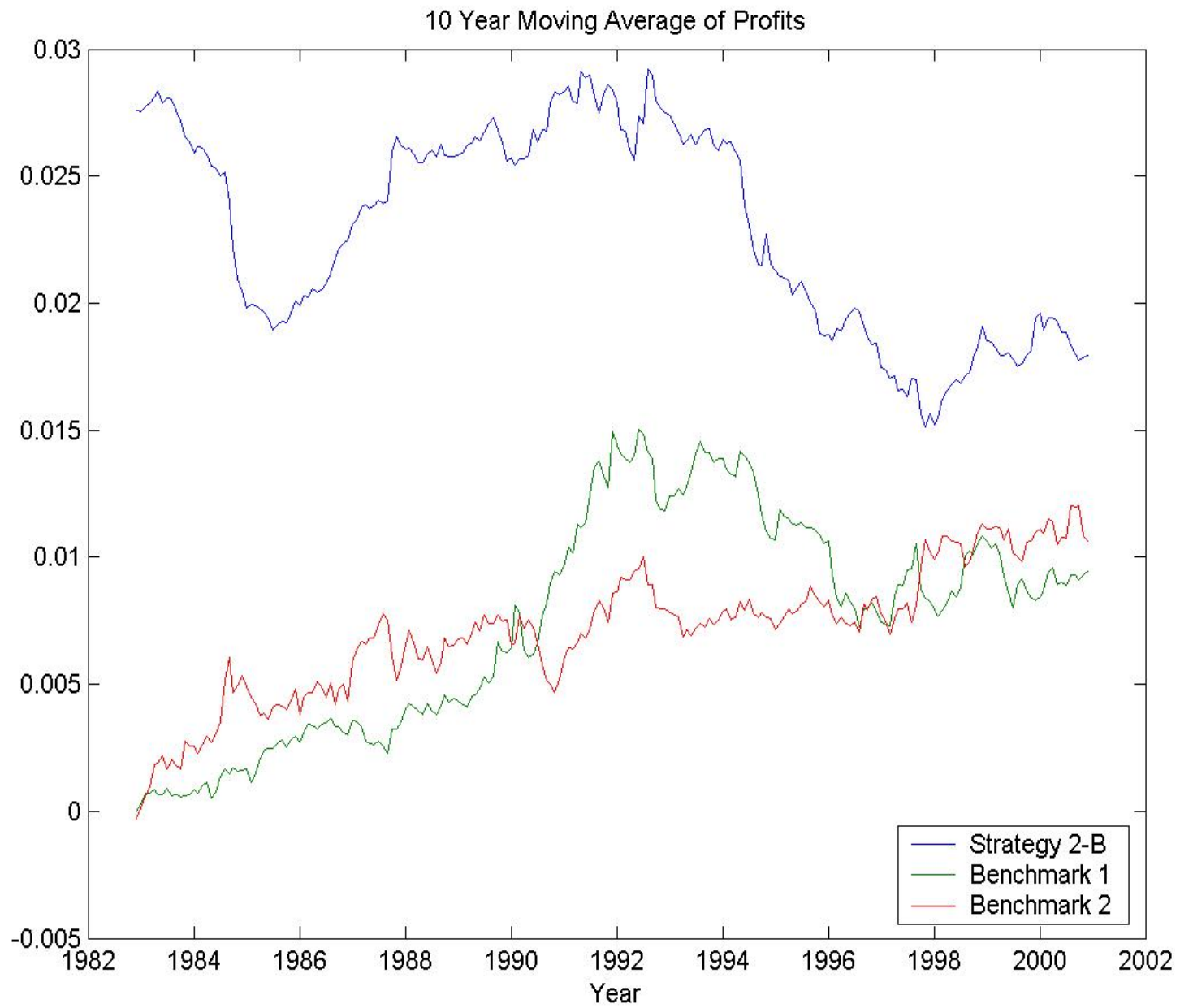


Figure 10

10-year Moving Average of Monthly Payoffs of Strategy 3-B

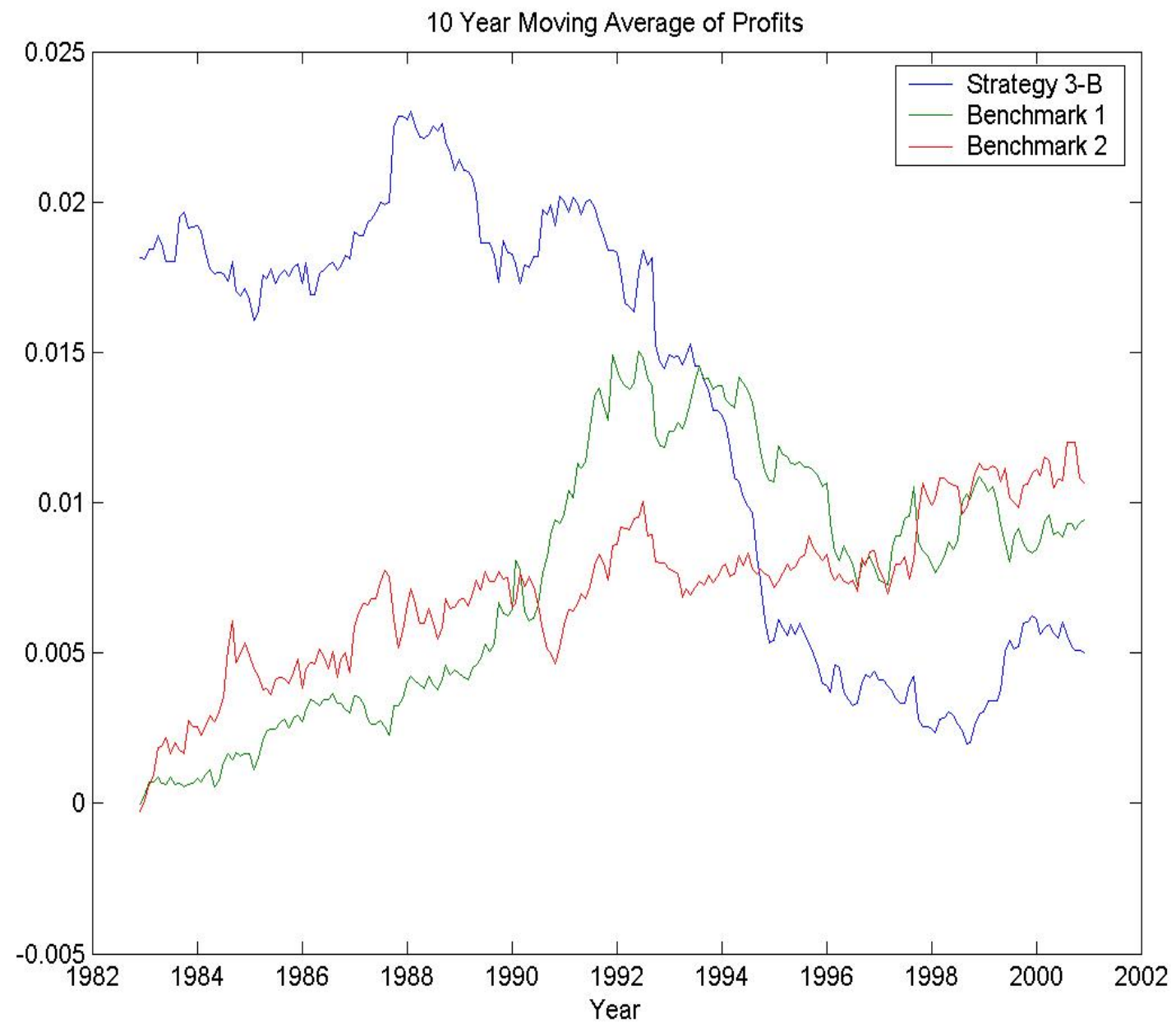

